\title{
Research on the Construction of the Evaluation System of Innovative Education in Colleges
}

\author{
Wang Shoujin \\ School of Information \& Control engineering \\ Shenyang Jianzhu University \\ Shenyang, China
}

\author{
Han Ziyang \\ School of Information \& Control engineering \\ Shenyang Jianzhu University \\ Shenyang, China
}

\begin{abstract}
With the continuous development of society, science and technology continue to enter this, China's education system is also in constant reform. From the reform of the situation, from the teaching idea to the evaluation system are all around the innovation education, innovation education as the center, and the teaching material evaluation system is the evaluation system is weak link, need to solve a lot of problems. This paper studies the construction of the evaluation system of the teaching material in innovative education, and analyzes the new mode and new method of the construction of innovative education system in Colleges and universities, in order to promote the development of innovation education in Colleges and universities.
\end{abstract}

Keywords-Innovative Education; Teaching Material Evaluation System; Higher Education

\section{INTRODUCTION}

In the context of the new century, innovation education has become the mainstream trend of contemporary education development, to ensure that the country continues to develop the trend, we must start from now, pay attention to the research of innovation education, to develop new innovative talents for our country. Innovation is an inexhaustible motive force for the development of innovative education to cultivate innovative talents for the community to adapt to the development trend of the society, the teaching material evaluation system is the system, the most important is the innovation of the teaching materials, teaching, and the relationship between teachers and students. The construction of teaching material evaluation system has a very important role in the development of the whole innovation education. The quality of teaching material directly affects the quality of teaching.

\section{The Challenge of InNOVATIVE EdUCATION EVALUATION SYSTEM}

Compared with the traditional evaluation system, the new evaluation system has a remarkable characteristic. In the new evaluation system, the main idea is to innovate education. This is different from the traditional teaching material to impart knowledge. It can be said to be a great challenge to the traditional evaluation system. The new teaching material evaluation system pays great attention to the student innovation to guide, has abandoned the traditional idea in the teaching material for the knowledge essence the idea, more outstanding to the student innovation ability and the innovation consciousness training. The new teaching materials to students as the center, the knowledge of the materials to learn the tools, knowledge in the teaching material to have a more modern spiritual guidance, not only knowledge of the traditional concept of knowledge, in the learning process, more attention to the ability of students to collect and deal with information, and the ability to cooperate and exchange, and resolutely resist the "nerdy" type of teaching, do not require students to die reading, pay attention to the cultivation of students' comprehensive ability.

In the present teaching material evaluation system, there are many problems that need to be improved. The existence of these problems has a serious impact on the construction and implementation of the evaluation system of innovative education materials. In the selection of teaching material, still use the old teaching materials, the choice of these materials also affect the development of innovative education, while the materials are constantly updated at the same time, the idea of innovative education is not fully reflected, just some minor changes. On the other hand, it is not enough to pay attention to the evaluation system of the teaching material, and the importance of the teaching evaluation system is not recognized. This makes the evaluation system construction work cannot be carried out, which seriously hinders the development of innovation education.

It is a key point to make clear the teaching material evaluation system and the quality of the teaching material, which is the key to innovation education. Innovative education is a challenge to traditional education, traditional education in our country is deeply rooted, but we believe that innovative education is more meaningful education, innovative education to meet the needs of the community, so that innovation education must be achieved, and the teaching material evaluation system is a key factor in innovation education, must continue to improve.

\section{NEW REQUiREMENTS FOR THE EVALUATION SYSTEM OF THE TEACHING MATERIAL OF THE INNOVATIVE EDUCATION}

\section{A. Highlight the Students as the Center}

The core idea of Innovative education is the 'peopleoriented', which is more prominent in the teaching material evaluation system, the dominant position of students, fully respect the differences between students, 
pay attention to students' individual development, can dig out the potential of students themselves, and constantly improve the students' comprehensive quality. The traditional teaching material evaluation system mainly takes the teachers teaching as the center, the innovation education idea may say that the people's understanding to the education, the more outstanding student's function in the appraisal system's construction. For students' opinions and suggestions to take full consideration, so as to continuously improve the adaptation of the materials, so that students like teaching materials, can be more reasonable application materials, so as to highlight the impact of teaching materials to students, to help students learn from the teaching materials, which is relative to the traditional education, the great changes We know that the traditional teaching material is more of a list of knowledge points, so that students in the process of reading, the emotional, indirectly lead to students to learn the knowledge of the material, which seriously affect the students' learning enthusiasm. In order to solve this problem, the teaching material of the innovative education needs to highlight the students' understanding.

\section{B. Highlight the Cultivation of Students' Ability}

Innovative education is the most prominent place in the traditional education is the cultivation of talents, the traditional education to cultivate the talent is a knowledge-based talent. However, this talent cannot adapt to the development of the society, innovative education to cultivate the talent is the ability to type, with a more prominent ability, but also pay more attention to the cultivation of innovative ability, which is in line with the current international situation.

As long as the traditional teaching material is to impart knowledge, as the main goal, more emphasis is on the students' knowledge of the memory, the application of knowledge in real life is not too much emphasis. In the practical course, some experiments are made to verify the nature of the experiment. The aim is to create some single technical personnel, while a lot of work for students to provide a lot of pressure, but also to restrict the development of students' free space. Typical exam oriented education highlights the importance of the results and the study of knowledge, and not pay attention to the study of students' ability, which greatly limits the students' thinking. Relatively speaking, innovation education is outstanding student's ability, especially the cultivation of innovation ability, in the teaching material, not only is the point of knowledge, but also set up a lot of open questions for students to explore, cultivate students' creative ability, exercise students' divergent thinking. The emphasis is on the conclusion and the results of the process of analysis, so that students focus on the method of the model, exercise students' ability to solve problems independently, rather than simply to the conclusion of memory. At the same time, the design of teaching material also highlights the importance of the experimental teaching material, the students' practical ability has higher requirements, students will not only do experiments, but also on this basis for the experimental innovation, so as to achieve the purpose of training students' practical ability and innovative ability.

\section{Highlight the Students' Awareness of Participation in Activities}

Innovative education has changed the traditional teaching mode of teachers and students, emphasizing students' learning and development in the mutual exchange, completely changed the traditional forms of teaching, students in mutual exchange and explore the knowledge. So in the textbook design, more is a variety of interactive activities to explore settings, in which teachers bear responsibility is the responsibility of guiding the students in accordance with the method in textbooks and learning materials, not to teach students the knowledge in the textbooks. Emphasize on the students' awareness of participation in activities and the requirements of the ability, so that students can have a strong interest in teaching materials, teaching materials to better play a role. While the rich activities also provide a guarantee for the innovation of teaching materials, students will have a variety of innovative ideas in the learning process, which is the development of teaching materials valuable comments.

\section{CONSTRUCTION OF THE EVALUATION S YSTEM OF INNOVATIVE EDUCATION MATERIALS}

\section{A. The Principle to be Followed in the Construction of the Evaluation System}

\section{1) Systematic Principle}

To know the teaching material evaluation system is a part of the innovation education, so in the construction process to ensure the system, which includes the system of the internal system also to ensure and the entire education system. System theory is a very important index system, each index system to form a functional group, these functional groups to have a good level, to ensure that the upper and lower levels of indicators, for the index system also pay attention to its timeliness. As we know, along with the development of the society, the problem is also constantly changing, to adjust with the changes of social concepts and social forms, so as to achieve a certain purpose.

\section{2) Operability Principle}

We know that a good system needs to be improved, so we must maintain a certain operability in the process of building the system. Comparison of the relationship between the various systems, horizontal comparison and vertical comparison, to find out the differences, reasonable planning, operational principle requires us to improve the evaluation system, from the comparison of the effective information, we must continue to choose, for which the weak link to improve, to ensure the sustainable development of the system.

\section{B. Several Aspects to be Considered in the Construction of the Evaluation System of the Teaching Material}

\section{1) Focus on the Innovation of Ideas}

The concept of innovation is the whole evaluation system of the concept of thinking, the entire evaluation system to highlight the students' innovative education as 
the main goal. In the concept, it is the concept of innovative education, the teaching material design highlights the personalized training, with Lenovo, creation, support, relationship and other functions, so that students have a better understanding of teaching materials based on better attention to teaching materials.

On the other hand, it is not only a method to teach students how to acquire knowledge, but also to teach students how to acquire knowledge.

\section{2 ) Focus on Innovation in Content}

First is the content of the integrity of the college teaching materials for students to have a certain knowledge to improve the content of the material should include the innovative education for college students' knowledge of the overall requirements, but also pay attention to the mutual connection between disciplines, let students learn from each other, so as to facilitate students' divergent thinking training is very important for students. To cultivate the students' theory and practice, the combination of this setting can make the students in the experiment continue to explore, to help students practice ability, but also to cultivate students' ability to find problems thinking. In the aspect of content development, it provides the way for students' personal development. It can be set up to meet the individual development of students, and provide resources for students to develop their personal development, so that students can master more knowledge and skills in the course of study.

\section{3 ) Focus on Organizational Innovation}

This innovation is mainly reflected in the textbooks, textbooks to change the existing mode, start innovation to provide some inspiration from the form, to the role of good at giving systematic guidance for students to acquire knowledge, cultivate the ability in teaching under the guidance of. Can be used to guide the way, can also be used to explore the way of scene simulation, the quality of the preparation of teaching materials is mainly reflected in the inspiration, the evaluation system of innovative materials also provides students with personalized teaching material selection program, according to the students' personal ability to learn to improve. At the same time in the practice of the case, to provide students with more freedom to play space, actively guide students to carry out innovative communication and communication, so as to enhance the students' ability of autonomous learning and thinking and communication skills, which are reflected in the preparation of teaching materials.

\section{4) Focus on Innovation in design form}

Teaching content is realized through the form of the material, so that the content can be fully embodied in the form of a close relationship. The innovation in the form of the teaching material is the requirement of the form of the teaching material, which can be reflected in the teaching material, which mainly includes the design of language, pictures and tables. In language, can be used in some of the more popular language, lively and vivid expression, students in reading can be more easily; In the picture, for some difficult to explain, to insert a number of pictures, the use of these images can be very good to help students understand the concept, played a very good auxiliary role; The design of the form is a supplement and description of some regular problems, and also can play a very good effect on the problem of the nature of the experiment. In the style of dialogue, the traditional exposition to the form of question and answer can play a very good guide to some of the problems, but also enhance the interaction between teachers and students, play a very good effect. In the layout of the full consideration to the students' visual experience and mental fatigue, etc., highlighting the focus, while the combination of related activities, so that students learn more easily.

\section{V.CONCLUSION}

Innovative education is an inevitable trend of modern social development, for the country concerned, in order to continue to develop in the fierce competition, we must strengthen education, education is the talent of the people, trained personnel innovative education more responsive to the development of contemporary society, so research and innovation education is necessary. Textbook evaluation system is the key to the development and improvement of textbooks, so the process of system construction to grasp the concept of innovation in education, a clear innovation in all aspects of education for the students ability requirements, highlighting the cultivation of students' ability, clear evaluation system construction challenge, as well as the principles of the build process and need to pay attention, so as to continue to innovate and improve to fully meet the requirements of innovation and education, thus promoting the development of innovative education for our country to cultivate more talents.

\section{REFERENCES}

[1] Liu Jinchao. Research into Establishing Innovation Education Textbook Evaluation System at Colleges and Universities [J]. Modern Education Forum, 2012,05:34-37.

[2] Yang Shiyong. Research into Establishing Innovation and Entrepreneurship Teaching System at Local Colleges [J]. Journal of Chifeng Institute (natural science edition), 2012,22:122-123.

[3] Zhao Ting, Chen Bing, Liang Ying. Research into Establishing Innovation Education Evaluation Index System of Colleges and Universities $[\mathrm{J}]$. Modern Economy and Information, 2014,11:419-420.

[4] Zhang Tianhua. Research into Establishing Entrepreneurship Education System and Evaluation System at Colleges and Universities and their Relationship [J]. Journal of Bohai University (Philosophic and social science edition), 2015,01:103-107.

[5] Xia Fengqin, Yang Jinlong. Research into Establishing Innovation Education and Teaching Evaluation System [J] Journal of Jilin Normal University (human and social science edition), 2011,01:90-92.

[6] Lifeng Mei, Tan Shaoyuan. Build Modern Distance Education Innovation Education Mode TV - TV Innovative Education Research Series [J] Social Sciences Review, 2010,08: 152-154 